\title{
SEM and Elemental Analysis of Phosphorus Concentrations Cullen Soil Amended with Biosolids Under Rainfall Simulation.
}

\author{
E.W.Westbrook*, C. J. Bronick*, A.Atalay* \\ *Agricultural Research Station, Virginia State University, Petersburg, VA 23806 USA
}

Municipal waste treatment plants treat domestic wastewater by dewatering and high temperature drying processes. The concentrated biosolid is rich in nutrients that may serve as a value-added product for plant growth. The application of biosolids to soil can increase crop yield and serve as a disposal mechanism for waste materials. However, there is a potential risk for increased phosphorus (P) and metals in runoff and percolation water. Soils with high P-sorbing capacity reduce the level of $\mathrm{P}$ in runoff and leachate [1]. Iron (Fe), aluminum (Al), and calcium $(\mathrm{Ca})$ are known to immobilize $\mathrm{P}$ in soil [2]. Increased $\mathrm{pH}$ and organic matter in biosolids-amended soils may further reduce the solubility of $\mathrm{Al}, \mathrm{Fe}, \mathrm{Ca}$ and $\mathrm{P}$ [3]. SEM can be a valuable tool in understanding the mineralogy and elemental distribution in soil.

The objectives of this study were to visualize the distribution of phosphorus and other elements with SEM and elemental micro-analysis and determine if valid as a tool for further investigation in soil P dynamics.

Biosolids were surface applied to an agricultural soil from Virginia. Cullen clay loam is a highly oxidized soil from the Piedmont region in Virginia with high concentrations of Al, Fe and Ca. Soil was packed in tilted aluminum beds. Simulated rain was applied at a rate of $65 \mathrm{~mm} \mathrm{~h}^{-1}$ for 45 minutes. Soil samples were air dried and analyzed for $\mathrm{C}, \mathrm{pH}$, metals and $\mathrm{P}$. This SEM investigation was conducted as a companion study to provide additional information on $\mathrm{P}$ dynamics in the soils.

Triplicate samples ( $1 \mathrm{~g})$ of control and biosolid treated samples of soils were taken before and after the simulated rainfall and processed for scanning electron microscopy (SEM) and energy dispersive x-ray analysis (EDX). Soil particles were firmly pressed onto double sticky taped aluminum stubs and carbon coated. Samples were stored in a dehumidifying chamber. Each sample was viewed in the Hitachi field emission scanning electron microscope (FESEM) at $20 \mathrm{kV}$. Three to five randomly chosen fields from each stub were imaged at 3,000x. Spectral mapping was performed at 5,000x or above using EDAX Genesis software to detect elemental composition, specifically $\mathrm{P}$, and provide relative concentrations.

Phosphorus is present in the soils in highly dispersed forms (Fig.2) as well as in concentrated regions (Figure 4). Phosphorus concentrations may be as mineral particles, inorganic coatings or inorganic matter. Phosphorus may be sorbed by the increased $\mathrm{C}$ in biosolid treated soils as well as cations such as $\mathrm{Ca}, \mathrm{Al}$ and $\mathrm{Fe}$. Phosphorus concentrations have a variable association with $\mathrm{C}$ and Fe, possibly as particle coatings (Fig.2, 4).

\section{References}

1. Elliott, H.A., G.A. O’Connor and S. Brinton. 2002. J. Environ. Qual. 31:681-689.

2. Lindsay, W.L. 1979. Chemical Equilibria in Soils. John Wiley \& Sons, New York, NY.

3. Zhang, M.K., Z.L. He, P.J. Stoffella, et al, 2004. J. Environ. Qual. 33: 373-379. 

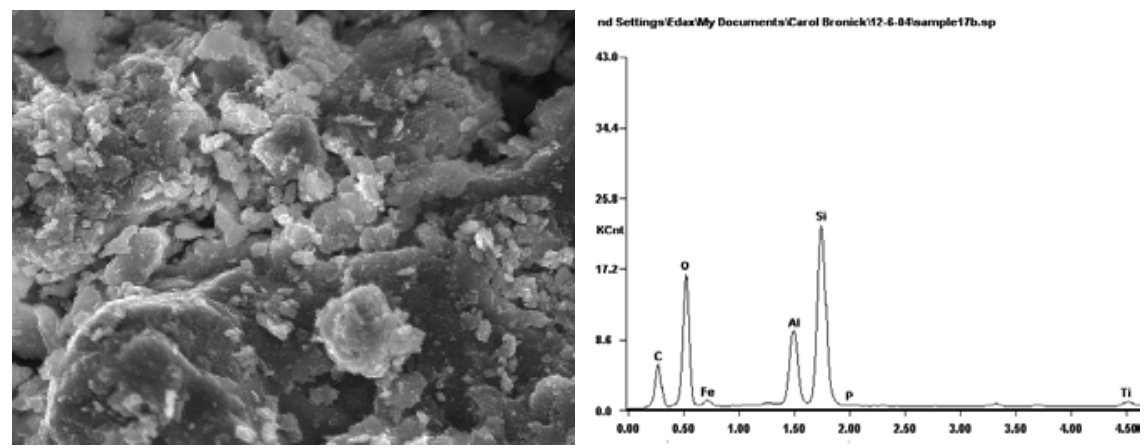

Fig. 1. SEM of Cullen type soil without biosolid after the rain with EDX. Accelerating voltage $=20 \mathrm{kV}$, counting live time $=50 \mathrm{sec}$. $10 \mu$

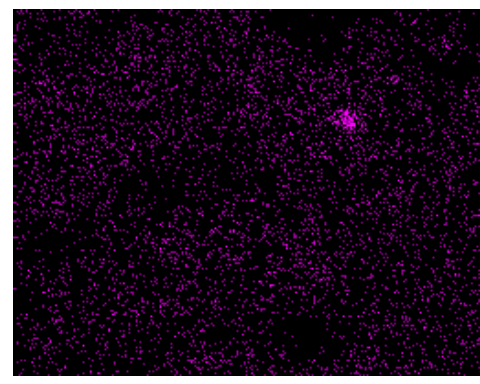

P (Phosphorus)

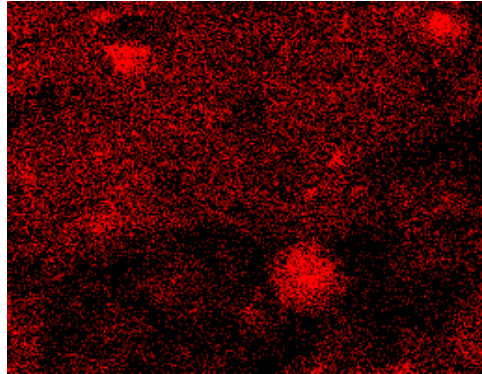

Fe (iron)

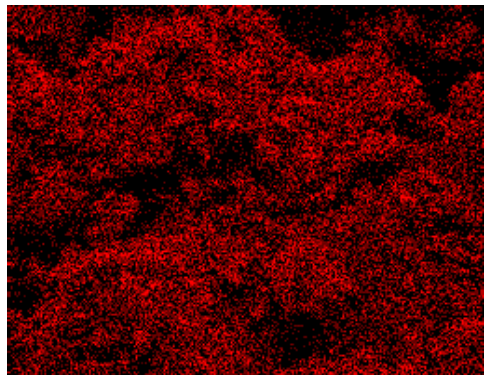

C (Carbon)

Fig. 2. Spectral mapping of SEM (Fig.1) showing dispersed P. Fe and $C$ are somewhat localized.

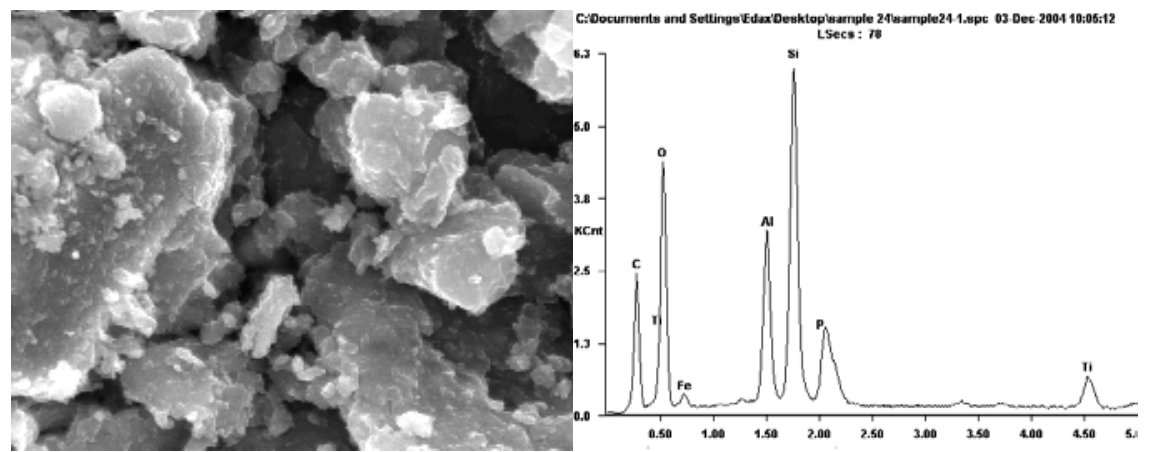

Fig. 3. SEM of Cullen type soil with biosoil after the rain with EDX. Accelerating voltage $=20 \mathrm{kV}$, counting live time $=50 \mathrm{sec}$. $10 \mu$

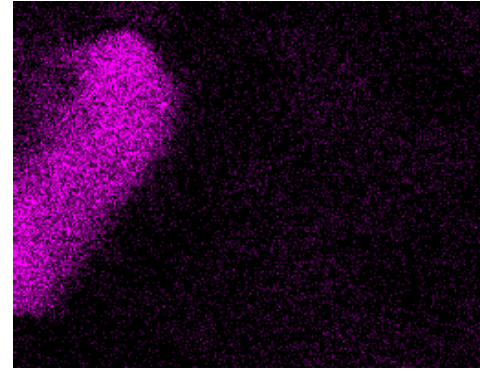

P (Phosphorus)

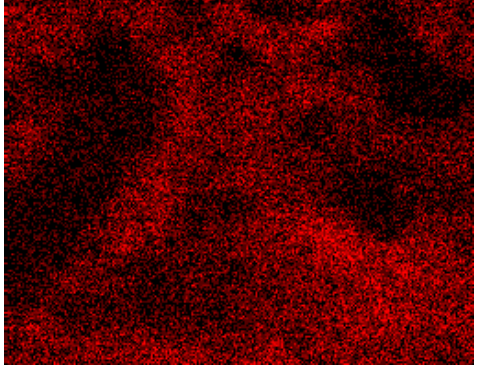

Fe (Iron)

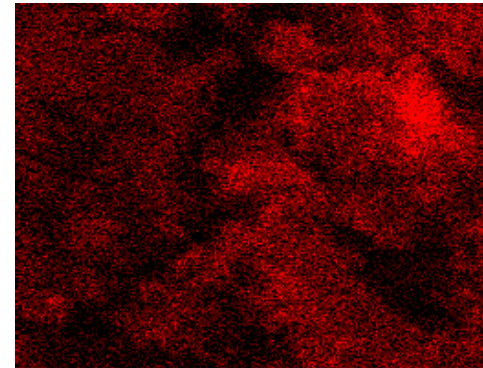

C (Carbon)

Fig. 4. Spectral mapping of SEM (Fig. 3) showing concentrated P, somewhat dispersed Fe and C. 